\title{
The Community Sports in the Construction of a Harmonious Society
}

\author{
Cao Xue \\ Xiangyang Vocational and Technical College Department of Basic Courses;xiangyang 441050, \\ China \\ 564985046@qq.com
}

Keywords: Community sports; harmonious society; sports facility.

\begin{abstract}
By literature review and investigation, the article offers some effective measures to solve some currently problems. Such as insufficiency of the community sports facility, lack of the perfect laws, the limited sports organization shortage of fund, no sports instructor. Taking these measures would improve largely the development of the community sports and enhance the process of harmonious society.
\end{abstract}

\section{Introduction}

The Fourth Plenary Session of the 16th CPC Central Committee put forward the requirements of building a harmonious socialist society. The harmonious society and the political, economic, cultural and sports activities of the society have promoted each other and developed together. Sports have also played an important role in building a harmonious society, The national sports and health level will certainly have a positive impact on building a socialist harmonious society. Community as the most basic social unit of human life, social development is actually based on the development of the community, community sports as the mainstay of community culture undoubtedly played a prominent role in community development, but also in the field of sports community sports There are a series of problems that affect the all-round development of sports and thus constrain the pace of a harmonious society. Therefore, to solve the problems of community sports, on the one hand, it is good for the health of the whole nation to be fit and healthy, is conducive to the harmonious coexistence of the entire people, is conducive to the overall health of the sports, is conducive to promoting the development of a harmonious society; on the other hand, It is also of practical significance to promote the prosperity of community sports culture through the relationship and cultivation of national spirit and the realization of the harmonious coexistence of man and society, man and nature.

\section{The status of community sports and existing problems}

\subsection{Community sports venues are relatively scarce}

As of December 31, 2003, the fifth national sports ground census ended in China. Our country (including all regions, systems, industries and various forms of ownership except Taiwan, Hong Kong and Macao, all over the country) 850080 various sports venues required by the census of sports venues have laid a good material foundation for the development of mass sports in our country. However, at the same time, it should be noted that our country has an average of 6.58 sports venues per 10,000 population and a per capita stadium area of 1.03 square meters. The absolute number of stadium facilities and the area of sports venues per capita are still small. Compared with some sports-related developed countries, Big difference. 


\begin{tabular}{|c|c|c|}
\hline Each system & Quantity (a) & Proportion \% \\
\hline SCHOOL & 549654 & 67.7 \\
\hline Organs and institutions & 75033 & 9.2 \\
\hline Township (town) village & 66714 & 8.18 \\
\hline Residential Area & 39637 & 4.86 \\
\hline Factory mine living area & 28300 & 3.47 \\
\hline Geriatric activity field & 13375 & 1.64 \\
\hline Hotel restaurant & 7259 & 0.89 \\
\hline Park & 5709 & 0.7 \\
\hline Square & 4975 & 0.61 \\
\hline Other & 21776 & 2.67 \\
\hline
\end{tabular}

The above materials show that at present one of the barriers to community sports activities is the lack of facilities and facilities. Community sports venues account for $27.66 \%$ (organs, institutions, towns and villages, residential areas, factories and mines, residential areas, parks and squares) This situation will limit the community sports activities, activities, content, affecting the community to carry out the full range of sports. The school gymnasium accounts for $67.7 \%$ of the total. However, the situation of opening to the outside world is not optimistic and needs to be further improved.

\subsection{The community can not make full use of large stadiums}

Large-scale stadiums are usually public sports facilities in a city. However, due to the government's financial allocation, the closed-door management mode has always been adopted, making the utilization of these facilities very low. In addition to some large-scale sports competitions or activities, Open to the community, idle for a long time.

\subsection{Laws and regulations are not sound}

At present, the development of community sports in our country is not standardized and the development of community sports in different places is unbalanced. Although China's "Sports Law" regulates the normal development of community sports, it is only a general law and lacks specific and effective pertinence to the actual conditions in various places.

\subsection{Sports management organization is not perfect}

Sports organization and management From the organizational structure point of view, multi-level community sports organizations have not been established, unable to carry out sports work hierarchically, the administrative color of its rich, less diversified organizational forms, with the current pluralistic community more prominent conflicts, community sports organizations Adopt one-way management mode, lack of interaction factors, management process also lack of supporting services, the potential of organizational systems can not be fully realized.

\subsection{Shortage of funds}

Government investment in community funds is insufficient, a serious lack of funds for community sports activities. Community sports is an important part of community construction. The lack of funding for community sports activities is an important factor restricting the development of community sports. This is due to the fact that at present China's overall economic strength is not strong and the government's investment in sports is relatively low. Sports administrations have serious deviations in the use of funds. On the other hand, due to the political effects of winning glory in the Olympics, they are easier to measure and measure. Naturally, they also lead to the preferences of certain leaders and departments, and the decoupling of communities and enterprises After that, the economic strength of the neighborhood committees was greatly weakened and cash-strapped. As a result, the funds for carrying out community sports activities naturally decreased and the initiative and enthusiasm for the work were greatly reduced.

\subsection{Physical instructors vacancies and other issues.}

The establishment of a high-quality community sports instructor and full-time staff with both professional theoretical knowledge and professional skills is an extremely urgent issue in community 
sports development at present. In spite of the training of a large number of social fitness instructors and full-time staffs in order to meet the fitness needs of community residents in recent years, the sports departments are not satisfied with the overall quality of their teams. Although most of them have a wealth of work experience, it is still not optimistic to accomplish the tasks set forth in the "Outline" and to achieve "scientific" physical fitness in the real sense.

\section{Community sports strategy to solve the problem}

\subsection{School sports facilities to the community}

Make full use of the existing sports facilities in the school, especially for those venues with no loss or loss. Equipment can be opened to the community free of charge. For venues requiring maintenance and repair, the community can be paid and open on holidays, Sundays or evenings , Obtain certain economic benefits, buffer, make up for the lack of community sports facilities. Therefore, the establishment of a combination of school sports and community sports management agencies, sports departments to change the vertical and closed management system, to strengthen horizontal ties; strengthen the management of school sports, to ensure the smooth progress of physical education in schools under the premise of the reasonable development of the existing school Sports facilities. The combination of school physical education and community physical education is conducive to promoting the nationwide fitness exercise to develop in depth and is conducive to using the social environment of the community and implementing education policies and policies. Schools can combine the strengths of both communities according to the specific conditions of the community, create a good environment for educating people and optimize the education of students, and jointly care for students' healthy growth. School sports provide sports talents and venue facilities for community sports, provide scientific research services and serve as Publicity and education. Community sports provide teachers and students in schools with a platform for social practice, professional internships and special skills. They also provide support for the scientific research in school sports. School sports to support community sports is not only a good form of promoting the development of community sports, but also a good form of promoting the development of campuses and communities. The combination of school physical education and community physical education is one of the important carriers and specific ways of realizing an overall well-to-do society. It is of great importance to further improve community building and implement the grand goal of building a well-to-do society in an all-round way proposed by the 16th CPC National Congress significance.

\subsection{Large-scale stadiums and ancillary venues facilities to the community}

The idleness of large-scale sports stadiums is incompatible with today's socialist market economy. Reform is imperative. Sports departments at all levels have also done a great deal of work. The former State Sports Commission also issued in 1995 a Notice on Opening Public Stadiums to the Public (GBQ [1995] No. 72) requires that sports administrative departments at all levels should, under the leadership of the local people's government, open public sports venues to the community as soon as possible in a planned, organized and step-by-step manner; and gradually explore ways to adapt Under the precondition of doing a good job in social activities, the existing public stadiums should be free to the community free of charge and the stadiums and facilities can be provided with paid services. Some supporting facilities Economic service activities; strengthen scientific management and continuously improve the utilization of existing stadiums and gyms. Relying on the development of community sports, changing the existing stadium "waiting 、 rely on" thinking, to achieve "farm by field" and promote social harmony.

\subsection{Improve laws and regulations, regulate community sports}

All localities should draw up laws and regulations that are suitable for the local community on the basis of the Sports Law and establish the authority of the community sports organizations and institutions. They should clearly define the venue facilities and funding sources for community sports and ensure that everyone has the right to participate in community sports. For example, to formulate a community and school sports venues to be shared, schools and communities are within the acceptable time, the school's sports venues open to the community, while community sports equipment is also 
open to schools, which is the development of community sports in Europe and the United States a success experience. Only in this way can we truly reflect the concept of community sports that "everyone participates and everyone enjoys" and guide the harmonious and healthy development of community sports.

\subsection{Improve the sports management organizations to ensure the healthy development of community sports}

At present, the community sports in our country lacks an effective sports management organization, which seriously affects the normal development of community sports in our country. Therefore, as soon as possible to establish a set of organizations to manage community sports activities, is to promote the healthy development of community sports in China an effective way. According to China's administrative division habits, can be divided into national, provincial, municipal 、 county (district) level 、 township (town) level five community sports management agencies. National and provincial management agencies are responsible for macro-level work such as formulation of guidelines, policies, strategies and tactics for community sports; municipal and county (district) -level management bodies are responsible for medium-level tasks such as helping macro-management organizations make decisions, Implement macro-management organization's development policy, policy, strategy and tactics, make middle-level arrangement according to the situation of community sports in this area; township (town) level understand the superior spirit and implement community sports specific work such as sports Venues, sports facilities, etc. to carry out regular community sports and recreational activities. The management agencies at all levels have their own duties, each responsible for each other, cooperate with each other and coordinate with each other to form a harmonious, sound and stable management system and create favorable conditions for the development of community sports.

\subsection{Multi-party financing to solve the shortage of community sports funding}

The funds for community sports in our country depend mainly on the government's financial appropriation. The proportion of investment by enterprises and individuals is very small, and residents' sports consumption is relatively small. This obviously can not meet the requirements of the masses for carrying out community sports activities. Therefore, the funding issue has become a constraint to community sports development Therefore, our country should learn from the successful experience of the countries and regions in Europe and the United States, and open up various channels for fund raising by the state, collectives and individuals. According to China's national conditions, we must first change our concept and establish the concept of "sports is health and happiness." At the same time, we should implement high, medium and low sports consumption services to meet the needs of sports consumption at different levels of community residents, The level and effectiveness of services on a new level. In addition, we actively seek sponsorship from the community and encourage enterprises to increase their investment in community sports. On the other hand, efforts should be made to develop the sports betting industry and foster the growth point of the sports industry.

\subsection{Vigorously develop the sports instructor, and promote the harmonious development of community sports}

Sports instructors play an important role in community sports, such as coaches, instructors and referees. They play an important role in promoting and popularizing community sports. However, the ratio of social sports instructors to population in our country is still quite large compared with that in Europe and the United States. The development of the sports instructor system in developed countries and regions is quite mature and has not yet been reflected in our country. Therefore, according to the needs of the development of community sports, community sports instructors should be vigorously cultivated, which not only focuses on the increase of the number, but also continuously improves their business level and establishes a stable community sports instructor team. Of course, the ways can be varied, for example, colleges and universities to train higher level of social sports instructors, you can also fully mobilize the power of society, to attract people with a certain expertise and enthusiastic social welfare activities to participate in, through certain qualifications can be . 


\section{Conclusion}

On December 31, 2003, the fifth census of sports venues ended in China. The results showed that there were not enough facilities for sports venues in our country. Community sports venues were even more scarce, with a per capita stadium of less than 1.03 square meters. For a series of problems existing in community sports, only by taking the facilities of school sports venues and venues of large stadiums open to schools, improving laws and regulations, standardizing community sports, improving sports management organizations and ensuring the healthy development of community sports, and raising funds to solve the problems of community In order to accelerate the harmonious development of community sports in order to speed up the progress of harmonious society, a series of measures should be taken to develop physical education instructors.

\section{References}

[1] Li Ping, Xiong Fei.A Theoretical Analysis of the Construction of Sports Ethics Value from the Perspective of Harmonious Society [J]. P. P., 2005, (9): 26-5.

[2] Zhao Peijun, Guo Chunyan. Discussion on the combination of school sports and community sports [J]. Sichuan Sport Science, 2004, (9).

[3] Wang Lingling. On the improvement of the utilization of sports facilities in the measures of [J]. Zhejiang Sports Science, 1999, (6): 2l-3.

[4] The Fifth National Sports Ground Census Office [S], 2005, (1).

[5] Chen Xilin, Zhou Yaqin. On the organic integration of school sports and community sports [J] .2002, (2): 26-1.

Deng Rongbiao.Enlightenment of community sports development in developed countries and regions in the world [J]. Shandong Sport Science and Technology, 2005, (9): 27-3.

[7] Luo Hanli, Peng Xionghui. Current situation and development countermeasures of urban community sports [J]. Journal of Physical Education, 2004, (1): 11-1.

[8] Zhang Zhongbao, Wang Xuguang Tianjin community sports status quo and development strategies [J]. Tianjin Institute of Physical Education, 2003, (18): 12-15. 